\title{
Biochemical and genetic characterization of a Prevotella intermedia/nigrescens-like organism
}

\author{
Eija Könönen, ${ }^{1}$ Jaana Mättö, ${ }^{2}$ Marja-Liisa Väisänen-Tunkelrott, ${ }^{1}$ \\ Ellen V. G. Frandsen, ${ }^{3}$ Ilkka Helander, ${ }^{4}$ Sirkka Asikainen, ${ }^{2}$ \\ Sydney M. Finegold ${ }^{5}$ and Hannele Jousimies-Somer ${ }^{1,5}$
}

Author for correspondence: Eija Könönen. Tel: +358 94744 8248. Fax: + 358947448238.

\footnotetext{
1 Anaerobe Reference Laboratory, National Public Health Institute, Mannerheimintie 166, FIN-00300 Helsinki, Finland

2 Institute of Dentistry, University of Helsinki, Helsinki, Finland

3 Department of Oral Biology, Royal Denta College, University of Aarhus, Aarhus, Denmark

4 VTT Biotechnology and Food Research, Espoo, Finland

5 Wadsworth VA Medical Center, West Los Angeles, CA, USA
}

\begin{abstract}
Thirty-three previously non-typable faintly pigmented Gram-negative anaerobic bacterial isolates, biochemically most closely related to Prevotella intermedia and Prevotella nigrescens, were analysed for enzymic reactions, cellular fatty acid (CFA) composition, electrophoretic mobility of malate and glutamate dehydrogenases, hybridization with $P$. intermedia and $P$. nigrescens species-specific oligonucleotide probes and, for genetic heterogeneity, by arbitrarily primed PCR (AP-PCR). P. intermedia ATCC $25611^{\top}$ and P. nigrescens ATCC $33563^{\top}$ were run in parallel for comparison. Twenty-nine isolates originated from the normal oral flora of 18 subjects (including five mother-child pairs), and four isolates from various infections. Except for a negative lipase reaction, enzymic profiles of the test isolates were similar to those of $\boldsymbol{P}$. intermedia and $\boldsymbol{P}$. nigrescens. Clustering of CFAs, electrophoretic mobility patterns, hybridization with DNA probes for $P$. intermedia and $P$. nigrescens, and AP-PCR band patterns of the test isolates differed from those of the type strains of $P$. intermedia and $P$. nigrescens, suggesting the existence, in humans, of a new anaerobic species of pigmented, moderately saccharolytic, indole-positive Gram-negative rods.
\end{abstract}

Keywords: Prevotella intermedia/nigrescens-like organism, fatty acid profiles, arbitrarily primed PCR, multilocus enzyme electrophoresis, oral microorganisms

\section{INTRODUCTION}

During a recent study on the oral anaerobic microflora in young children and their mothers $(17,18)$ we occasionally isolated Gram-negative, faintly pigmented bacterial strains that did not clearly belong to any known species. The isolates shared several biochemical characteristics with Prevotella intermedia and Prevotella nigrescens (28). For instance, our isolates were indole-positive and displayed special-potency antimicrobial disk profiles, carbohydrate fermentation profiles and short-chain fatty acid profiles of metabolic end products similar to $P$. intermedia and $P$. nigrescens. However, some phenotypic characteristics consistently differed from those of $P$. intermedia and $P$. nigrescens: a negative lipase reaction on egg yolk agar and weak pigmentation (buff to $\tan$ ) on rabbit laked blood

Abbreviations: AP-PCR, arbitrarily primed PCR; CFA, cellular fatty acid; $\mathrm{GDH}$, glutamate dehydrogenase; MDH, malate dehydrogenase; MLEE, multilocus enzyme electrophoresis; PINLO, $P$. intermedia/nigrescens-like organism.
(RLB) agar. We tentatively called this new species/ subspecies candidate a $P$. intermedia/nigrescens-like organism (PINLO).

The separation of the serologically and genetically heterogenic $P$. intermedia (previously Bacteroides intermedius) $(3,11,13)$ into two species, $P$. intermedia and $P$. nigrescens, was confirmed based on differences in DNA-DNA homology and mobilities of the metabolic enzymes malate dehydrogenase $(\mathrm{MDH})$ and glutamate dehydrogenase (GDH) in multilocus enzyme electrophoresis (MLEE) (28). To separate phenotypically closely related $P$. intermedia and $P$. nigrescens from each other we have successfully used genotypic methods, i.e. hybridization with species-specific oligonucleotide probes and the arbitrarily primed PCR (AP-PCR) $(21,22)$.

The $P$. intermedia/nigrescens group can be found in the oral cavity as well as extra-oral sites in both healthy and diseased conditions $(6,15,16,21,30)$. However, some differences may exist within this group: $P$. intermedia has been reported in association with oral 
infections, such as periodontitis, more frequently than $P$. nigrescens $(3,9,10,22)$, whereas $P$. nigrescens seems to be more common in children than $P$. intermedia $(9$, $22)$. According to our preliminary reports $(17,18)$ PINLO was detected from the oral cavities of adult women in whom its presence was associated with periodontal health, as well as from the oral cavities of young children. Certain enzymic characteristics among bacterial populations are of clinical interest. Both $P$. intermedia and $P$. nigrescens are capable of totally degrading human immunoglobulin Al ( $\operatorname{IgA} 1)$; this may play a role in oral infections (8). We have also observed high frequencies of $\beta$-lactamase activity among oral pigmented Prevotella species isolated from young children (19).

The aim of the present study was to characterize our PINLO isolates and to clarify the taxonomic position of PINLO by using a comprehensive approach. This characterization included the semiquantitative determination of preformed enzymes, the determination of IgAl degradation and $\beta$-lactamase production, cellular fatty acid (CFA) analysis, determination of MDH and GDH electrophoretic mobilities, and hybridization with $P$. intermedia and $P$. nigrescens species-specific oligonucleotide probes. In addition, AP-PCR was used in species identification as well as to examine the genetic heterogeneity among our PINLO isolates.

\section{METHODS}

Bacterial strains. Altogether 33 oral isolates were available from 23 mother-child pairs which had been previously examined $(17,18) ; 13$ PINLO isolates from oral surfaces of nine young children and 16 PINLO isolates from saliva of nine mothers (in five cases PINLO was simultaneously isolated from the mother and her child). The samples were cultured as described previously (16). In addition, four suspected PINLO candidates originating from various infections of four unrelated subjects were included in the present study; two strains were from peri-implantitis (AHN 12313 and AHN 18349), one strain was from a patient with osteomyelitis of the mandible (AHN 18857), and one isolate was from a pulmonary aspirate (AHN 10991 = WAL 11083). P. intermedia ATCC $25611^{\mathrm{T}}$ and $P$. nigrescens ATCC $33563^{\mathrm{T}}$ were used for comparison. The isolates were revived from frozen stocks $\left(-70^{\circ} \mathrm{C}\right)$ and subcultured for further analyses.

Enzymic profiling. The profiles of 19 preformed bacterial enzymes were semiquantitatively determined using commercial API ZYM kits (bioMérieux) according to the manufacturer's instructions. Colour reactions were interpreted after incubation of the kits in air at $37^{\circ} \mathrm{C}$ for $4 \mathrm{~h}$. A negative $\alpha$-fucosidase reaction was confirmed by using individual chromogenic Rosco Diagnostic tablets (Rosco Diagnostica) (5). To examine IgA1 degradation, human dimeric IgA1 (Kah) was isolated from the serum of a patient with multiple myeloma as previously described (7). Bacterial colonies from agar plates were suspended in $40 \mu \mathrm{lof}$ a $1 \mathrm{mg}$ $\mathrm{ml}^{-1}$ solution of $\mathrm{IgAl}$ and tested for degradation of $\operatorname{IgA} 1$ after $1,4,24$ and $48 \mathrm{~h}$ by immunoelectrophoresis (14). $\beta$ Lactamase activity was tested by using the chromogenic cephalosporin disk test (AB BIODISK) (25).
CFA analysis. CFA compositions were identified by using the computerized database library compiled by Microbial Identification System (MIS; Microbial ID, Inc.), Moore 3.8 or 3.9 version as a reference. Briefly, a loopful of isolated colonies was inoculated into tubes containing $10 \mathrm{ml}$ prereduced peptone/yeast extract/glucose broth in an anaerobic chamber. The tubes were incubated at $37^{\circ} \mathrm{C}$ for $2-3 \mathrm{~d}$. After centrifugation the supernatant was discarded and the sedimented cells were processed by saponification, methylation, extraction and basic wash as described by Moore $e t$ al. (24). The CFAs were separated by a HP 5890A gas chromatograph equipped with a $25 \mathrm{~m} \times 0.2 \mathrm{~mm}$ fused silica capillary column and flame ionization detector (HewlettPackard). In addition, a combined GLC-MS was used to confirm the identity of certain CFAs. A two-dimensional plot and a dendrogram in Euclidian Distance (ED) scale were generated by the cluster analysis of the quantitative CFA profiles included in the MIS database library.

Multilocus enzyme electrophoretic analysis. Electrophoretic mobilities of $\mathrm{MDH}$ and GDH were analysed using polyacrylamide gels in non-denaturing conditions with slight modifications of a previously described method (22). Bacterial cells from 2-3 d-old Brucella agar cultures suspended in HEPES buffer were disrupted by sonication and centrifuged. The supernatant was electrophoresed in polyacrylamide gel consisting of $4 \%$ stacking gel and $10 \%$ running gel for $\mathrm{MDH}$ or $7.5 \%$ running gel for GDH. The gels were run at $100 \mathrm{~V}$ for $2 \mathrm{~h}(\mathrm{MDH})$ or at $150 \mathrm{~V}$ for $3 \mathrm{~h}$ $(\mathrm{GDH})$ in Tris base/glycine buffer using a Mini-Protean II electrophoresis apparatus (Bio-Rad). $\mathrm{MDH}$ was visualized in a solution containing malic acid $\left(2 \mathrm{mg} \mathrm{ml}^{-1}\right)$, and $\mathrm{GDH}$ in a solution containing glutamic acid $\left(20 \mathrm{mg} \mathrm{ml}^{-1}\right)$. All chemicals were from Sigma.

Hybridization with $\boldsymbol{P}$. intermedia and $\boldsymbol{P}$. nigrescens speciesspecific oligonucleotide probes. The chromosomal DNA from $P$. intermedia, $P$. nigrescens and PINLO cultures grown for 3-4 d was extracted using the method of Moncla et al. (23) with our modification (27). Hybridizations with $P$. intermedia and $P$. nigrescens species-specific oligonucleotide probes were performed as previously described (22). Briefly, target DNA was transferred to nylon membrane, fixed by UV irradiation and hybridized at $49{ }^{\circ} \mathrm{C}$ separately with plasmid pKK3535 (1) and with $P$. intermedia and $P$. nigrescens species-specific oligonucleotide probes synthesized according to the $16 \mathrm{~S}$ rRNA sequence data published by Dix et al. (4): $P$. intermedia, 5'-GGT CCT TAT TCG AAG GGT AAA TGC-3' (corresponding to $1 \mathrm{Bi}-1$ ); and $P$. nigrescens, 5'-ATG AGG TAC ATG CAA TGG CGC ACA-3' (2Bi-1) (2). The probes were labelled with the DIG oligonucleotide tailing kit and the colorimetric detection was performed using the DIG DNA detection kit (Boehringer Mannheim).

AP-PCR analysis. Five microlitres of diluted chromosomal DNA (approx. $5 \mathrm{ng}$ ) were used as template DNA in a $50 \mu \mathrm{l}$ reaction volume consisting of $0.2 \mathrm{mM}$ each dNTP (Pharmacia Biotech), $0.5 \mu \mathrm{M}$ primer, $10 \mathrm{mM}$ Tris $/ \mathrm{HCl} \mathrm{pH} \mathrm{8.3,}$ $50 \mathrm{mM} \mathrm{KCl}, 4 \mathrm{mM} \mathrm{MgCl}_{2}$ and $2.5 \mathrm{U}$ AmpliTaq DNA polymerase (Perkin Elmer Cetus). The random sequence oligonucleotides OPA-13 (5'-CAGCACCCAC-3') and OPA-03 (5'-AGTCAGCCAC-3') were chosen from the five tested primers (OPA-03, OPA-05, OPA-07, OPA-13, OPA-17) to be used as primers in AP-PCR. The temperature profile in a thermocycler (Perkin Elmer Cetus) was 35 cycles as follows: $94^{\circ} \mathrm{C}$ for $1 \mathrm{~min}, 32^{\circ} \mathrm{C}$ for $2 \mathrm{~min}, 72^{\circ} \mathrm{C}$ for $2 \mathrm{~min}$. The initial denaturation was at $94^{\circ} \mathrm{C}$ for $5 \mathrm{~min}$ and final extension at 
$72{ }^{\circ} \mathrm{C}$ for $5 \mathrm{~min}$. Amplification products were analysed electrophoretically in $1 \%$ agarose gel containing $0.5 \mu \mathrm{g}$ ethidium bromide $\mathrm{ml}^{-1}$ and photographed under UV illumination using the Polaroid MP4 system with 667 film. A DNA ladder (1 kb) (Gibco BRL, Life Technologies) was used as a molecular mass standard in gel electrophoresis.

\section{RESULTS}

Table 1 summarizes the key phenotypic characteristics of $P$. intermedia ATCC $25611^{\mathrm{T}}, P$. nigrescens ATCC $33563^{\mathrm{T}}$ and our 33 PINLO isolates.

\section{Enzymic reactions}

API ZYM patterns of the examined PINLO isolates were indistinguishable from those of $P$. intermedia and $P$. nigrescens reference strains. In five cases $\alpha$-fucosidase remained negative by the API ZYM system but a parallel $\alpha$-fucosidase test by Rosco tablets confirmed positive reactions. All isolates induced total degradation of $\operatorname{IgA} 1$ as revealed by absence of precipitation lines in immunoelectrophoresis. For most isolates complete degradation was observed after incubation for $24 \mathrm{~h}$ and, for the remaining isolates, after incubation for $48 \mathrm{~h}$ (and for one isolate $72 \mathrm{~h}$ ). $\beta$ Lactamase production was more frequent among the strains from children than among those from the mothers; $\beta$-lactamase-positive strains were found in $7 / 9$ children but only in $3 / 9$ mothers (Table 2 ).

\section{CFA composition and cluster analysis}

Numerical CFA analysis of the 33 PINLO isolates revealed anteiso- $\mathrm{C}_{15: 0}$, iso- $\mathrm{C}_{15: 0}$, iso- $3-\mathrm{OH}$ iso- $\mathrm{C}_{17: 0}$ (summed feature 11 ; identity confirmed by GLC-MS) in quantitative order, and also an unknown CFA with an equivalent chain-length (ECL) of 13.570 (summed

Table 1. Key characteristics of 33 PINLO isolates from 22 subjects compared with the reference strains $P$. intermedia ATCC $25611^{\top}$ and $P$. nigrescens ATCC $33563^{\top}$

\begin{tabular}{|c|c|c|c|}
\hline & PINLO & $\begin{array}{l}\text { ATCC } \\
25611^{T}\end{array}$ & $\begin{array}{l}\text { ATCC } \\
33563^{\mathrm{T}}\end{array}$ \\
\hline Pigment on RLB agar* & Buff/tan & Black & Black \\
\hline Colistin sensitivity & + & + & + \\
\hline Lipase reaction* & - & + & + \\
\hline Indole production & + & + & + \\
\hline \multicolumn{4}{|l|}{ Sugar fermentation } \\
\hline Glucose & + & + & + \\
\hline Lactose & $-\dagger$ & - & - \\
\hline Sucrose & + & + & + \\
\hline $\begin{array}{l}\text { Major metabolic end } \\
\text { products in GLC }\end{array}$ & $\mathrm{A}, \mathrm{S}_{+}^{+}$ & A, $S$ & A, S \\
\hline
\end{tabular}

* Follow-up to $10 \mathrm{~d}$.

$\dagger$ Except two lactose-fermenting isolates from the same mouth. $\ddagger \mathrm{A}$, Acetic acid; S, succinic acid. feature 3), as major CFAs ( $>10 \%$ of the total CFAs) (Table 3). The quantitative CFA pattern resembled the corresponding pattern of $P$. nigrescens ATCC $33563^{\mathrm{T}}$. The CFA analysis gave several alternatives for the identification of the examined PINLO isolates (Table 2 ). Despite this incoherent identification, most of the PINLO isolates formed a homogeneous group in the cluster analyses, differing from $P$. intermedia ATCC $25611^{\mathrm{T}}$ and $P$. nigrescens ATCC $33563^{\mathrm{T}}$ (Figs 1, 2). Five PINLO isolates (AHN 8792, 9778, 10006, 10991 and 12313; Fig. 1) clustering apart from the main cluster had a higher proportion of iso- $\mathrm{C}_{15: 0}$ (range $20 \cdot 3-26.5 \%$ ) than the other PINLO isolates (range $7 \cdot 7-17 \cdot 6 \%$ ) in the main cluster.

\section{Electrophoretic migration of MDH and GDH}

MLEE patterns of $P$. intermedia ATCC $25611^{\mathrm{T}}, P$. nigrescens ATCC $33563^{\mathrm{T}}$, and PINLO differed from each other (Table 2). $P$. intermedia showed faster MDH and GDH mobilities and P. nigrescens slower $\mathrm{MDH}$ and GDH mobilities than PINLO isolates. One PINLO isolate (AHN 18349) showed slightly different MDH mobility (M3; Table 2) from the other 32 PINLO isolates which had similar MDH mobilities. Two GDH groups with intermediate mobilities in relation to $P$. intermedia and $P$. nigrescens were found among the examined PINLO isolates: the faster GDH group of PINLO isolates (G2) differed only slightly from the GDH group of the type strain of $P$. intermedia (G1) as seen in Fig. 3.

\section{Species-specific oligonucleotide probing}

All isolates hybridized with the universal pKK3535 probe, and the type strains of $P$. intermedia and $P$. nigrescens hybridized with corresponding speciesspecific probes. The examined PINLO isolates did not hybridize with either $P$. intermedia or $P$. nigrescens species-specific oligonucleotide probes, thus supporting a separate species status for PINLO.

\section{AP-PCR}

AP-PCR with oligonucleotide OPA-13 revealed a common band in the $2.4 \mathrm{~kb}$ region for all 33 PINLO isolates, whereas $0.9 \mathrm{~kb}$ or $1.3 \mathrm{~kb}$ bands, typical for $P$. intermedia and $P$. nigrescens, respectively (21), were not found (Fig. 4). Among the 29 examined isolates from nine mothers and nine children, the AP-PCR amplification using primers OPA-03 and OPA-13 revealed 10 different AP-PCR profiles each. When the results with both primers were combined, a total of 14 clearly different AP-PCR banding patterns was obtained. In addition, two AP-PCR types, each in two unrelated subjects, were so closely related that they could not be definitely separated (banding patterns $1+$ and $1-$, and $7+$ and $7-$; Table 2 ). In six subjects, two to four PINLO isolates were available but only one AP-PCR type was found per subject. In the five related mother-child pairs from whom PINLO was simul- 
Table 2. Summary of present results

\begin{tabular}{|c|c|c|c|c|c|c|}
\hline \multirow[t]{2}{*}{ Strain } & \multirow[t]{2}{*}{ Source* } & \multirow[t]{2}{*}{$\begin{array}{l}\text { Identification } \\
\text { proposed by MIS } \\
\text { (first choice) }\end{array}$} & \multicolumn{2}{|c|}{$\begin{array}{c}\text { Electrophoretic } \\
\text { mobility } \\
\text { group } \dagger\end{array}$} & \multirow[t]{2}{*}{$\begin{array}{c}\text { AP-PCR } \\
\text { group }\end{array}$} & \multirow[t]{2}{*}{$\begin{array}{c}\beta \text {-Lactamase } \\
\text { activity }\end{array}$} \\
\hline & & & MDH & GDH & & \\
\hline \multicolumn{7}{|l|}{ ATCC } \\
\hline $25611^{\mathrm{T}}$ & & P. intermedia & M1 & G1 & & \\
\hline $33563^{\mathrm{T}}$ & & P. nigrescens & M4 & G4 & & \\
\hline \multicolumn{7}{|l|}{ AHN $\ddagger$} \\
\hline 8418 & $\mathrm{~m} 1$ & P. nigrescens & M2 & G2 & 4 & - \\
\hline 9153 & $\mathrm{ml}$ & $P$. intermedia & M2 & G2 & 4 & - \\
\hline 10371 & $\mathrm{c} 2$ & P. nigrescens & M2 & G3 & 13 & + \\
\hline 8275 & $\mathrm{~m} 3$ & $B$ D $28 \S$ & M2 & G3 & $1-$ & - \\
\hline 8441 & $\mathrm{~m} 6$ & P. nigrescens & M2 & $\mathrm{G} 2$ & 3 & + \\
\hline 8401 & c6 & P. nigrescens & M2 & G2 & 3 & + \\
\hline 8404 & c6 & P. intermedia & M2 & G2 & 3 & + \\
\hline 8431 & $c 6$ & P. veroralis $\|$ & M2 & G2 & 3 & + \\
\hline 8792 & c8 & $B$ D28 & M2 & G3 & 9 & + \\
\hline 8964 & $\mathrm{~m} 11$ & P. nigrescens & M2 & G2 & 2 & - \\
\hline 8858 & c11 & P. nigrescens & M2 & G2 & 6 & + \\
\hline 8977 & $\mathrm{c} 11$ & P. nigrescens & M2 & G2 & 6 & + \\
\hline 9283 & $\mathrm{~m} 14$ & P. veroralis & M2 & G2 & 5 & - \\
\hline 9301 & c14 & $B \mathrm{D} 28$ & M2 & G2 & $1+$ & + \\
\hline 9419 & $\mathrm{~m} 15$ & P. nigrescens & M2 & G2 & $7-$ & - \\
\hline 9423 & $\mathrm{~m} 15$ & $P$. nigrescens & M2 & G2 & $7-$ & - \\
\hline 9424 & $\mathrm{~m} 15$ & P. nigrescens & M2 & G2 & $7-$ & - \\
\hline 9425 & $\mathrm{~m} 15$ & P. nigrescens & M2 & G2 & $7-$ & - \\
\hline 9517 & c15 & P. nigrescens & M2 & G3 & 11 & + \\
\hline 9738 & $\mathrm{~m} 19$ & P. nigrescens & M2 & G2 & 10 & - \\
\hline 9739 & $\mathrm{~m} 19$ & $B \mathrm{D} 28$ & M2 & G2 & 10 & - \\
\hline 9741 & $\mathrm{~m} 19$ & P. nigrescens & M2 & G2 & 10 & - \\
\hline 9778 & $\mathrm{~m} 19$ & P. tannerae & M2 & G2 & 10 & - \\
\hline 9761 & c19 & P. nigrescens & M2 & G2 & 10 & - \\
\hline 9793 & c19 & P. nigrescens & M2 & G2 & 10 & - \\
\hline 9899 & $\mathrm{~m} 20$ & P. nigrescens & M2 & G2 & 12 & + \\
\hline 9954 & c21 & $B \mathrm{D} 28$ & M2 & G2 & $7+$ & - \\
\hline 10006 & $\mathrm{~m} 22$ & P. tannerae & M2 & G2 & 14 & + \\
\hline 10290 & $\mathrm{c} 23$ & P. veroralis & M2 & G3 & 8 & + \\
\hline 12313 & Peri-implantitis & P. tannerae & M2 & G2 & & - \\
\hline 18349 & Peri-implantitis & P. nigrescens & M3 & G3 & & - \\
\hline 18857 & Osteomyelitis & P. intermedia & M2 & G2 & & + \\
\hline 10991 & Pulmonary aspirate & P. tannerae & M2 & G3 & & - \\
\hline
\end{tabular}

* $\mathrm{m}$, Mother; c, child; numbers refer to the 23 mother-child pairs originally examined $(16,17)$.

$\dagger$ Mobility groups are presented in numerical order; the fastest mobility group $=1$.

$\ddagger$ AHN, Anaerobe Helsinki Negative.

$\S B$ D28, Bacteroides D28 [currently Prevotella tannerae (indole-negative)].

|| Prevotella veroralis (indole-negative).

taneously detected, two mother-child pairs each shared a similar AP-PCR type (Figs 4 and 5; Table 2).

\section{DISCUSSION}

In the present study using several biochemical and genetic methods, the examined 29 isolates from normal oral flora and four isolates from various infections showed characteristics that clearly separated them from both $P$. intermedia and $P$. nigrescens. In fact, the differentiation of PINLO from the phenotypically similar $P$. intermedia and $P$. nigrescens was simpler than the differentiation between $P$. intermedia and $P$. nigrescens. The key phenotypic characteristics for this 
Table 3. Main CFAs (> $3 \%$ of total CFAs) of PINLO isolates, $P$. intermedia ATCC $25611^{\top}$ and $P$. nigrescens ATCC $33563^{\top}$

\begin{tabular}{|lrcc|}
\hline CFA & $\begin{array}{c}\text { PINLO } \\
(\boldsymbol{n}=\mathbf{3 3})^{*}\end{array}$ & $\begin{array}{c}\text { ATCC } \\
\mathbf{2 5 6 1 1}^{\mathrm{T}} \dagger\end{array}$ & $\begin{array}{c}\text { ATCC } \\
\mathbf{3 3 5 6 3}^{\mathrm{T}}{ }^{\dagger}\end{array}$ \\
\hline Iso-C $_{14: 0}$ & $6 \cdot 6 \pm 2 \cdot 1$ & $11 \cdot 1$ & $10 \cdot 0$ \\
Iso-C $_{15: 0}$ & $14 \cdot 4 \pm 4 \cdot 5$ & $10 \cdot 5$ & $16 \cdot 3$ \\
Anteiso-C $_{15: 0}$ & $33 \cdot 6 \pm 2 \cdot 0$ & $27 \cdot 6$ & $31 \cdot 6$ \\
C $_{16: 0}$ & $3 \cdot 8 \pm 1 \cdot 3$ & $2 \cdot 2$ & $2 \cdot 4$ \\
UN 13.570 & $10 \cdot 8 \pm 2 \cdot 1$ & $0 \cdot 9$ & $7 \cdot 1$ \\
Iso-3-OH C $_{17: 0} \S$ & $13 \cdot 5 \pm 2 \cdot 5$ & $21 \cdot 5$ & $11 \cdot 8$ \\
\hline
\end{tabular}

$*$ Mean $\% \pm$ SD.

$\dagger$ Mean $\%$ of two runs.

\$Summed feature 3 .

$\S$ Summed feature 11 (CFA confirmed by GLC-MS).

Euclidian Distance

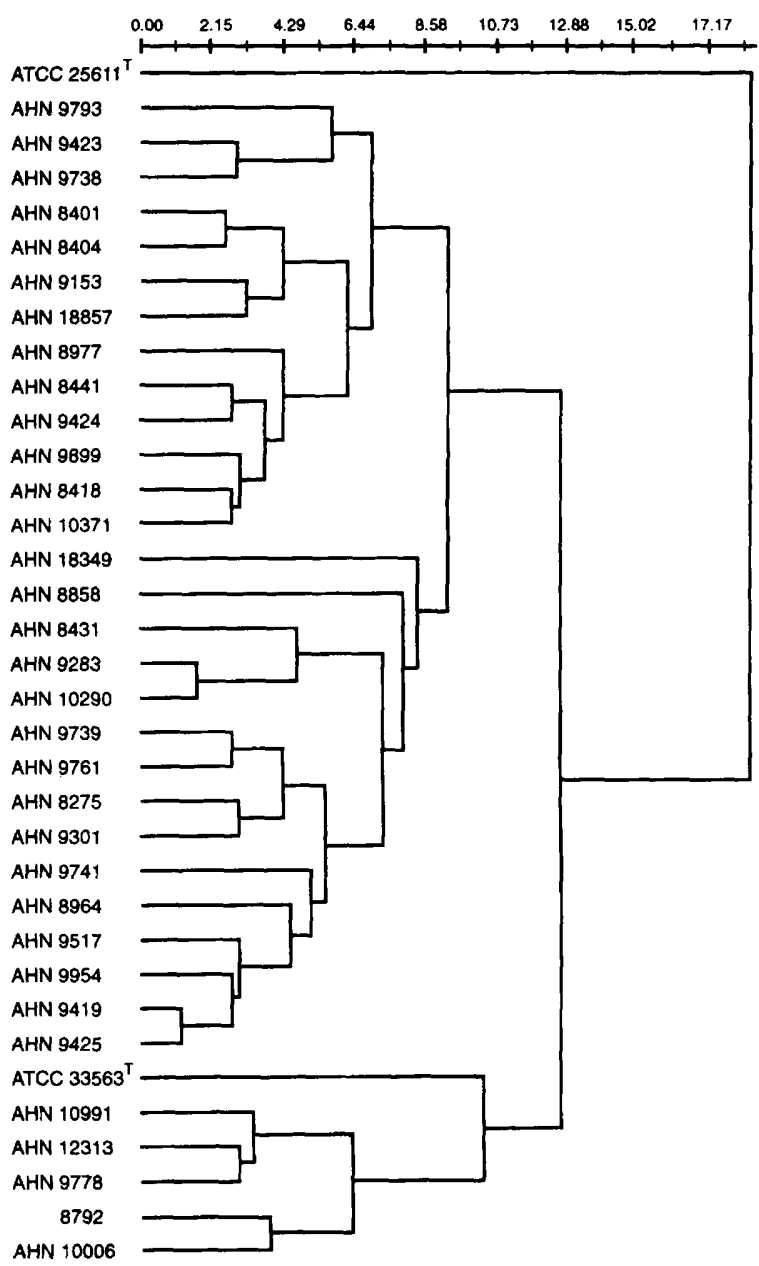

Fig. 1. Dendrogram of 33 PINLO isolates, and the reference strains $P$. intermedia ATCC $25611^{\top}$ and $P$. nigrescens ATCC $33563^{\top}$ generated by cluster analysis of CFA profiles.

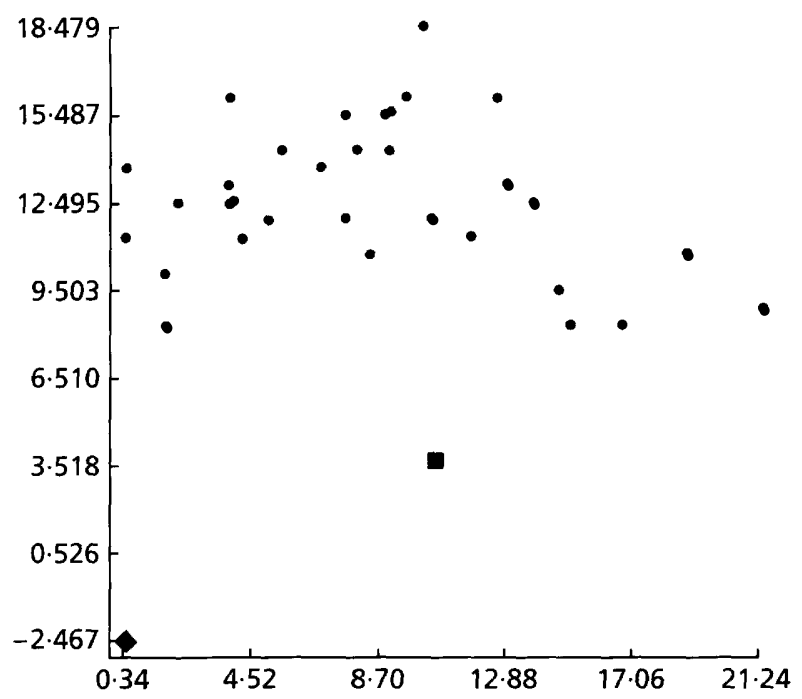

Fig. 2. Two-dimensional plot of 33 PINLO isolates (0), and the reference strains $P$. intermedia ATCC $25611^{\top}(\bullet)$ and $P$. nigrescens ATCC $33563^{\top}(\boldsymbol{\square})$, generated by principal component analysis of CFA profiles.

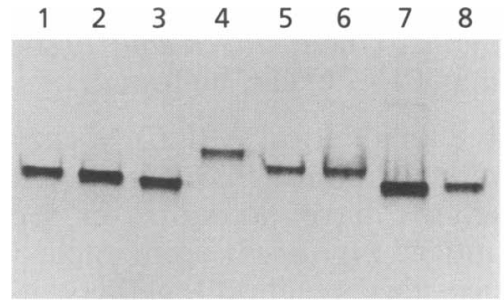

Fig. 3. GDH mobilities of $P$. intermedia ATCC $25611^{\top}, P$ nigrescens ATCC $33563^{\top}$ and PINLO. Lanes 1 and 2, PINLO (mobility group G2); lane 3, P. intermedia ATCC $25611^{\top}(\mathrm{G} 1)$; lane 4, $P$. nigrescens ATCC $33563^{\top}$ (G4); lanes 5 and 6, PINLO (G3); lanes 7 and 8, PINLO (G2).

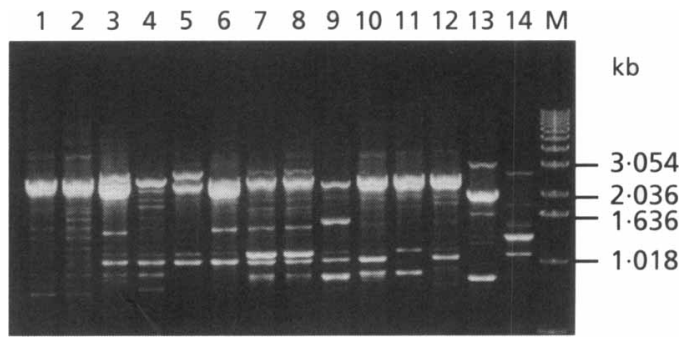

Fig. 4. $A P-P C R$ profiles obtained using primer OPA-13. Lanes 1-10, PINLO isolates from five mother-child pairs; lanes 11 and 12, PINLO isolates from two unrelated mothers; lane 13, $P$. intermedia ATCC $25611^{\top}$; lane $14, P$. nigrescens ATCC $33563^{\top}$; $M$, molecular mass standard. Note a common band of $2.4 \mathrm{~kb}$ among the PINLO isolates. 


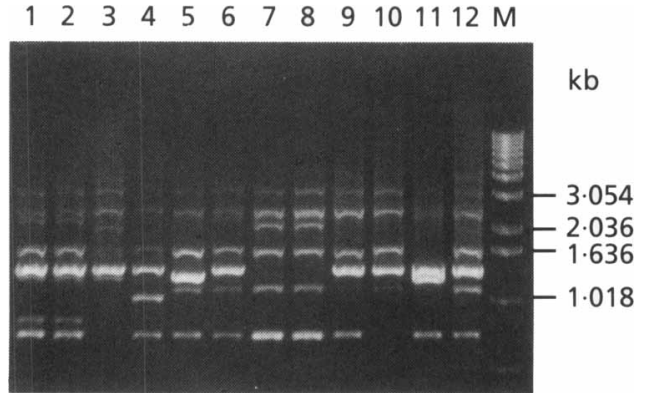

Fig. 5. AP-PCR profiles of PINLO isolates obtained using primer OPA-03. Lanes $1-12$ as in Fig. $4 ; M$, molecular mass standard.

weakly pigmented Gram-negative anaerobic species are the positive indole reaction but negative lipase reaction. The reported negative lipase reaction for $P$. nigrescens ATCC $33563^{\mathrm{T}}$ (= NCTC 9336) $(26,28)$ does not apply to clinical strains or to the type strain of $P$. nigrescens according to our own experience or other reports $(9,22)$. The discrepancy between the results may be due to a different follow-up time for the lipase reaction. It is notable that the inability to ferment lactose does not definitely discriminate $P$. intermedia, P. nigrescens or PINLO from other pigmented Prevotella species, since occasional lactose-fermenting strains belonging to the $P$. intermedia/nigrescens group $(3,9)$ as well as PINLO can be found.

PINLO shared an identical API ZYM enzyme pattern with $P$. intermedia and $P$. nigrescens. API ZYM enzyme reactions have no value in separating $P$. intermedia and $P$. nigrescens from each other, but a positive $\alpha$-fucosidase reaction together with a positive indole reaction (spot test) reliably separates $P$. intermedia and $P$. nigrescens from other related species (5). It is notable that testing $\alpha$-fucosidase activity with an individual tablet substrate revealed more positive reactions than testing with API ZYM.

CFA profiling has shown its value as a technically easy and reproducible method for taxonomic studies of several Gram-negative anaerobic species (24). In the present study, the quantitative CFA pattern of PINLO isolates resembled the CFA pattern of $P$. nigrescens, while $P$. intermedia produced a higher proportion of iso-3-OH- $\mathrm{C}_{17: 0}$ but a lower proportion of an unknown CFA with an equivalent chain-length of 13.570 than $P$. nigrescens and PINLO. This result could refer to a closer relationship of PINLO to P. nigrescens than to $P$. intermedia. However, the more advanced methods, namely MLEE, species-specific oligonucleotide probes and AP-PCR, that have been used for differentiation of $P$. intermedia and $P$. nigrescens $(21,22,26,28)$, did not identify PINLO isolates as $P$. intermedia or as $P$. nigrescens. The enzymic mobility patterns of our PINLO isolates located between the fastest mobility group of $P$. intermedia and the slowest mobility group of $P$. nigrescens. Interestingly, two different GDH mobility groups were formed for the PINLO isolates suggesting even greater heterogeneity among this group. The interpretation of $\mathrm{MDH}$ and, especially GDH mobilities can be difficult because of only slight differences between the bands of $P$. intermedia/ $P$. nigrescens/PINLO. According to Frandsen et al. (8), the current use of only two enzymes (MDH and GDH) for the species differentiation between $P$. intermedia and $P$. nigrescens may not be sufficient, as some overlapping in electrophoretic mobilities can be observed, and therefore the use of MLEE analysis for identification should be based on several enzymes.

By using OPA-13 as a primer in AP-PCR, Mättö et al. (21) found a common band in the region $0.9 \mathrm{~kb}$ for $P$. intermedia and in the region $1.3 \mathrm{~kb}$ for $P$. nigrescens. In the present study, a common band was observed for the examined PINLO isolates in the region $2.4 \mathrm{~kb}$, but more data are needed to show whether this band is a species-specific amplicon and applicable for routine identification of PINLO.

In the present study we combined the AP-PCR results revealed by two primers (OPA-03 and OPA-13), and thus greater heterogeneity was obtained than by using just one primer. Inter-individual genetic heterogeneity of PINLO was confirmed, as at least 14 different APPCR types were detected from oral samples from 18 subjects. The finding is consistent with the previously observed inter-individual heterogeneity of other oral pigmented Prevotella species (Prevotella melaninogenica, $P$. intermedia, $P$. nigrescens) (20-22). Among the five mother-child pairs that harboured PINLO in the oral cavity, in two cases a mother and her child shared an identical AP-PCR type, thus indicating a vertical transmission of this organism between these related subjects. On the other hand, the clonal diversity among PINLO seemed to be limited intra-individually; only a single AP-PCR type was found even when several isolates from the same mouth (two to four isolates in six subjects each) were available for analysis. According to our previous results revealed by ribotyping or AP-PCR, more than one strain of $P$. nigrescens and $P$. intermedia can simultaneously colonize the oral cavity $(21,22)$. The simultaneous colonization of the oral cavity by several strains of the same species was even more obvious with another frequently found pigmented Gram-negative anaerobic rod, $P$. melaninogenica (20). However, the limited number of PINLO isolates per subject may have influenced this unexpected finding.

Certain oral pigmented Gram-negative anaerobes (previously black-pigmented Bacteroides spp.) have been intensively studied during the past two decades because of their suspected connection with destructive periodontal diseases $(3,29,30)$. Despite the research interest, hardly any observations of bacteria resembling PINLO are to be found in the pertinent literature. One explanation may be the selective lifting of darkpigmented colonies for further identification in which case the faint pigmentation of PINLO may have been overlooked. Another possibility is the absence of PINLO in periodontally diseased sites $(17,18)$. Re- 
cently Guillot \& Mouton (12) described new PCRDNA probe assays for the specific identification and detection of $P$. intermedia and $P$. nigrescens, and reported one strain that could not be assigned to either $P$. intermedia or $P$. nigrescens despite similar biochemical reactions. Pearce et al. (26) reported two atypical strains with intermediate electrophoretic mobilities of MDH and GDH among $P$. intermedia and $P$. nigrescens strains; one of these strains was lipasenegative resembling PINLO. Further characteristics that would allow better comparison were not provided and furthermore, no detailed clinical data or information on the origin of these strains were available. Despite the lack of information on PINLO in the literature, it seems to be a common colonizer of the oral cavity; our original material consisted of 23 mother-child pairs of whom nine mothers and nine children were culture-positive for PINLO $(17,18)$. Besides these PINLO isolates originating from the 'normal oral microflora' in the present material, we had some isolates from severe oral and extra-oral infections indicating the opportunistic pathogenic nature of PINLO. The ability to degrade human IgA1 totally may act as a potential virulence factor for PINLO as well as for $P$. intermedia and $P$. nigrescens (8). Our observation that oral PINLO isolates, especially from children, frequently produced $\beta$ lactamase may have clinical significance when treating paediatric anaerobic infections of oral origin.

In agreement with our previous observations on the weak colony pigmentation and negative lipase reaction, the present comprehensive investigation including CFA cluster analyses, MDH and GDH electrophoretic mobilities, AP-PCR amplification as well as negative hybridization with $P$. intermedia and $P$. nigrescens species-specific oligonucleotide probes, indicates that PINLO seems to form a new pigmented, moderately saccharolytic, indole-positive species different from $P$. intermedia and $P$. nigrescens. Other nucleic-acid-based methods, e.g. DNA-DNA hybridization or $16 \mathrm{~S}$ rRNA sequencing coupled with more comprehensive enzyme mobility profiling are warranted to assess the exact taxonomic position of PINLO.

\section{ACKNOWLEDGEMENTS}

We thank R. Heine and M. Piekkola for their technical assistance. The Academy of Finland, the Sigrid Juselius Foundation, the Novo Nordisk Foundation and the Veterans Administration Merit Review are acknowledged for financial support.

\section{REFERENCES}

1. Brosius, J., Ullrich, A., Raker, M. A., Gray, A., Dull, T. J., Gutel, R. R. \& Noller, H. F. (1981). Construction and fine mapping of recombinant plasmids containing the $r r n$ B ribosomal RNA operon of E. coli. Plasmid 6, 112-118.

2. Chuba, P. J., Pelz, K., Krekeler, G., De Isele, T. S. \& Göbel, U. (1988). Synthetic oligodeoxynucleotide probes for the rapid detection of bacteria associated with human periodontitis. J Gen Microbiol 134, 1931-1938.

3. Dahlén, G., Wikström, M., Renvert, S., Gmür, R. \& Guggenheim, B. (1990). Biochemical and serological characterization of Bacteroides intermedius strains isolated from the deep periodontal pocket. J Clin Microbiol 28, 22692274.

4. Dix, K., Watanabe, S. M., McArdle, S., Lee, D. I., Randolph, C., Moncla, B. \& Schwartz, D. E. (1990). Species-specific oligodeoxynucleotide probes for the identification of periodontal bacteria. J Clin Microbiol 28, 319-323.

5. Durmaz, B., Jousimies-Somer, H. R. \& Finegold, S. M. (1995). Enzymatic profiles of Prevotella, Porphyromonas, and Bacteroides species obtained with the API ZYM system and Rosco diagnostic tablets. Clin Infect Dis 20 (suppl. 2), S192-S194.

6. Finegold, S. M., Strong, C. A., McTeague, M. \& Marina, M. (1993). The importance of black-pigmented gram-negative anaerobes in human infections. FEMS Immunol Med Microbiol 6, 77-82.

7. Frandsen, E. V. G. (1994). Carbohydrate depletion of immunoglobulin Al by oral species of gram-positive rods. Oral Microbiol Immunol 9, 352-358.

8. Frandsen, E. V. G., Poulsen, K. \& Kilian, M. (1995). Confirmation of the species Prevotella intermedia and Prevotella nigrescens. Int $J$ Syst Bacteriol 45, 429-435.

9. Fukushima, H., Moroi, H., Inoue, J., Onoe, T., Ezaki, T., Yabuuchi, E., Leung, K.-L., Walker, C. B., Clark, W. B. \& Sagawa, H. (1992). Phenotypic characteristics and DNA relatedness in Prevotella intermedia and similar organisms. Oral Microbiol Immunol 7, 60-64.

10. Gharbia, S. E., Haapasalo, M., Shah, H. N., Kotiranta, A., Lounatmaa, K., Pearce, M. A. \& Devine, D. A. (1994). Characterization of Prevotella intermedia and Prevotella nigrescens isolates from periodontic and endodontic infections. $J$ Periodontol 65, 56-61.

11. Gmür, R. \& Guggenheim, B. (1983). Antigenic heterogeneity of Bacteroides intermedius as recognized by monoclonal antibodies. Infect Immun 42, 459-470.

12. Guillot, E. \& Mouton, C. (1997). PCR-DNA probe assays for identification and detection of Prevotella intermedia sensu stricto and Prevotella nigrescens. J Clin Microbiol 35, 1876-1882.

13. Johnson, J. L. \& Holdeman, L. V. (1983). Bacteroides intermedius comp. nov. and descriptions of Bacteroides corporis sp. nov. and Bacteroides levii sp. nov. Int J Syst Bacteriol 33, $15-25$.

14. Kilian, M. (1981). Degradation of immunoglobulins A1, A2, and $\mathrm{G}$ by suspected principal periodontal pathogens. Infect Immun 34, 757-765.

15. Könönen, E. (1993). Pigmented Prevotella species in the periodontally healthy oral cavity. FEMS Immunol Med Microbiol 6, 201-205.

16. Könönen, E., Asikainen, S., Saarela, M., Karjalainen, J. \& Jousimies-Somer, H. (1994). The oral gram-negative anaerobic microflora in young children and longitudinal changes from edentulous to dentate mouth. Oral Microbiol Immunol. 9, 136-141.

17. Könönen, E., Jousimies-Somer, H., Wolf, J. \& Asikainen, S. (1995). Suspected periodontopathogens in saliva in relation to periodontal status. Eur J Oral Sci 103, S40.

18. Könönen, E., Jousimies-Somer, H., Wolf, J. \& Asikainen, S. 
(1995). Influence of maternal periodontal status on colonization of suspected periodontopathogens in children. $J$ Dent Res 74, 469.

19. Könönen, E., Nyfors, S., Măttö, J., Asikainen, S. \& JousimiesSomer, H. (1997). $\beta$-Lactamase production by oral pigmented Prevotella species isolated from young children. Clin Infect Dis 25 (suppl. 2), S272-S274.

20. Könönen, E., Saarela, M., Karjalainen, J., Jousimies-Somer, H., Alaluusua, S. \& Asikainen, S. (1994). Transmission of oral Prevotella melaninogenica between a mother and her young child. Oral Microbiol Immunol 9, 310-314.

21. Măttö, J., Saarela, M., von Troil-Lindén, B., Alaluusua, S., Jousimies-Somer, H. \& Asikainen, S. (1996). Similarity of salivary and subgingival Prevotella intermedia and Prevotella nigrescens isolates by arbitrarily primed polymerase chain reaction. Oral Microbiol Immunol 11, 395-401.

22. Măttö, J., Saarela, M., von Troil-Lindén, B., Könönen, E., Jousimies-Somer, H., Torkko, H., Alaluusua, S. \& Asikainen, S. (1996). Distribution and genetic analysis of oral Prevotella intermedia and Prevotella nigrescens. Oral Microbiol Immunol 11, 96-102.

23. Moncla, B. J., Braham, P., Dix, K., Watanabe, S. \& Schwartz, D. (1990). Use of synthetic oligonucleotide DNA probes for the identification of Bacteroides gingivalis. J Clin Microbiol 28, 324-327.

24. Moore, L. V. H., Bourne, D. M. \& Moore, W. E. C. (1994). Comparative distribution and taxonomic value of cellular fatty acids in thirty-three genera of anaerobic gram-negative bacilli. Int J Syst Bacteriol 44, 338-347.

25. O'Callaghan, C. H., Morris, A., Kirby, S. M. \& Shingler, A. H. (1972). Novel method for detection of beta-lactamases by using a chromogenic cephalosporin substrate. Antimicrob Agents Chemother 1, 283-288.

26. Pearce, M. A., Dixon, R. A., Gharbia, S. E., Shah, H. N. \& Devine, D. A. (1996). Characterization of Prevotella intermedia and Prevotella nigrescens by enzyme production, restriction endonuclease and ribosomal RNA gene restriction analyses. Oral Microbiol Immunol 11, 135-141.

27. Saarela, M., Măttó, J., Asikainen, S., Jousimies-Somer, H., Torkko, H., Pyhälä, L., Stucki, A.-M., Hannula, J., Hölttä, P. \& Alaluusua, S. (1996). Clonal diversity of Actinobacillus actinomycetemcomitans, Porphyromonas gingivalis and Prevotella intermedia/nigrescens in two families. Anaerobe $\mathbf{2}$, 19-27.

28. Shah, H. N. \& Gharbia, S. E. (1992). Biochemical and chemical studies on strains designated Prevotella intermedia and proposal of a new pigmented species, Prevotella nigrescens sp. nov. Int $J$ Syst Bacteriol 42, 542-546.

29. Tanner, A. C. R., Haffer, C., Bratthall, G. T., Visconti, R. A. \& Socransky, S. S. (1979). A study of the bacteria associated with advancing periodontitis in man. J Clin Periodontol 6, 278-307.

30. van Winkelhoff, A. J., van Steenbergen, T. J. M. \& de Graaff, J. (1988). The role of black-pigmented Bacteroides in human oral infections. J Clin Periodontol 15, 145-155. 